\title{
Integration of Different ERP Systems on Mobile Devices
}

\author{
Álvaro Lozano ${ }^{1}$, Ana Belen Gil ${ }^{1}$, and Tiancheng $\mathrm{Li}^{2}$ \\ ${ }^{1}$ Department of Computer Science and Automation, University of Salamanca \\ Plaza de la Merced, s/n, 37008, Salamanca, Spain \\ \{loza, abg\}@usal.es \\ ${ }^{2}$ School of Mechatronics, Northwestern Polytechnical University, \\ Xi'an, 710072, P.R. China \\ t.c.li@mail.nwpu.edu.cn
}

\begin{abstract}
Nowadays a lot of enterprises work with ERP systems. It usefulness is generally used in office environments and different enterprises which offer this software are developing mobile applications. These mobile applications work with their own system and they don't usually work in other platforms. Currently any mobile application can communicate with more than one ERP system because each one has its own communications methods. This article presents a system that expect unify the communication between different ERP systems and allows mobile applications to communicate with them in a homogeneous way.
\end{abstract}

Keywords: ERP, Mobile, VTD-XML, XPATH, REST, Android.

\section{Introduction}

Nowadays a lot of enterprises decide to start using ERP (Enterprise Resource Planning). These systems manage a lot of daily tasks of the different enterprises sectors: production, logistics, allocation, stock, consignment, invoicing, etc. Their implementations can be adapted to the business that they manage [1]. Currently ERP systems can be found in office environments and managed by qualified staff. This kind of software requires a previous training to take advantage of it.

The mobiles devices are every time smaller, lighter and they have improved the performance, these are the reason why it seems a good idea transferring part of the ERP usefulness to these devices [3].

Transferring ERP feasible process to a mobile device will allow an enterprise staff outside of the office to make distance specific operations on the ERP software thanks to nice interface normally presented on mobile applications.

These applications aim to transform mobile devices into work tools that are completely integrated into staff's daily work, getting closer to typical notions of pervasive computing [6] Enterprises not only will use the applications in these mobile devices as work tools, but also to gather information and thus make better their internal processes based on acquired knowledge achieved by that information [7] 
Nowadays several companies that commercialize ERP systems are directing this software to SaaS [2] [28] [31] [30] Architectures and they also have platforms to develop applications EMA (Enterprise Mobile Application) [4] [26] [32] which make possible linking mobile devices of different platforms and the ERP software offered by them.

The main trouble is the fact that different ERPs don't have the same public interface, that is, we don't have neither a communication protocol nor common information [8] [9]. Currently the enterprises who offer ERP software invest a lot of time and money in the development of native applications on different platforms to use them with their own ERP. This means that there are no applications which can link with other ERPs.

Along this paper a system to integrate different ERPs is presented as a possible solution of this trouble. We expect to unify different linking methods of the different ERP systems by developing a standard of communication and information and adapting this information of every system to the standard. This will allow enterprises to develop mobile applications which are able to operate with different ERP systems.

This article is divided as follows: section 2 describes the state of the art; section 3 presents the proposed model; section four describes the results obtained and the conclusions respectively.

\section{Background}

There are many applications that ERP Software companies offer to customers. Such as SAP Business One which has management applications on Windows Phone, IOS and Android platforms. Exist both web applications as native applications on the market but they all have operations in the ERP for which they were designed [37] [38] [39]. Companies usually distribute this kind of software they certify official partners who are responsible for developing applications. Official Partners use SDKs, APIs or communication offered by ERP systems with the outside which are commonly SOAP web services [5] [22] [25] [27] [29].

Due to communication with the outside of the ERP systems, companies as Jitterbit [34] have emerged. Jitterbit performs transformations of data streams of different types of web services.

This paper aims to transform not only the data but set a standard to unify communication and information that can be given between these ERP systems and mobile or web applications.

The ERP market is varied and there are many different systems from diverse companies. The best known is chosen SAP and despite only having a market share of $22 \%$ [33] [10] [21] [23] [24].

\section{Proposed Reasoning System}

The proposed system aims to create an integration of different ERPs so that it provides a common interface to all of them. It facilitates the creation of mobile 
applications that are compatible with multiple ERP systems. The system initially presents the integration of three ERP systems from two leading companies in the sector [10] such as Microsoft and SAP. ERP systems are initially chosen Microsoft Dynamics NAV, Microsoft Dynamics AX and SAP Business One.

The system will display the following general structure figure 1:
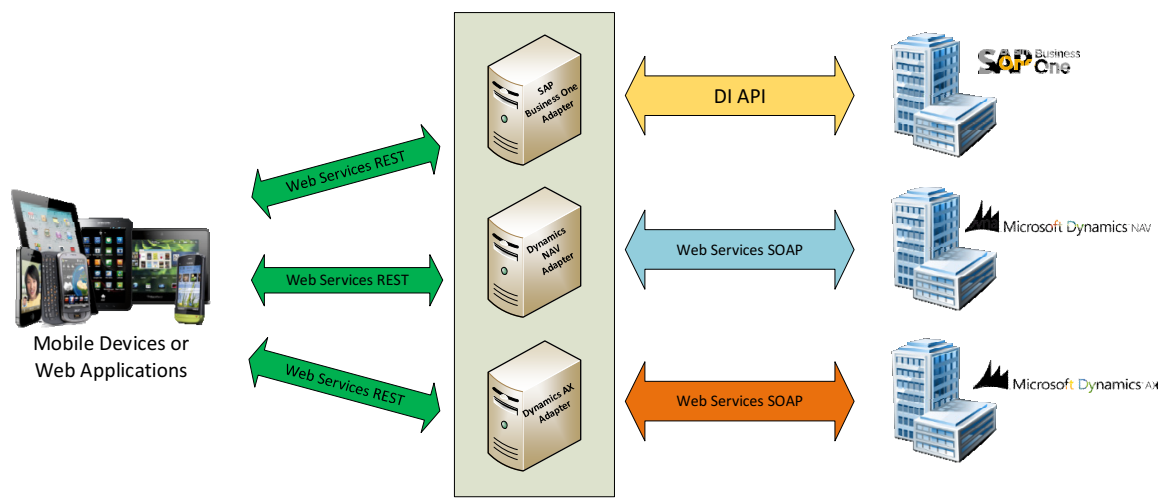

Fig. 1. General structure

For each one of the ERPs integrated into system there should be an adapter where the ERP information will be transformed to the established information standard and vice versa.

The kind of communication that will exist between mobile devices and adapters will be homogeneous. This communication is based on a set of REST services [20] [19] [18] that will may be used by web or mobile applications.

The development of this system poses two challenges mainly:

- Perform a standard of information between ERP systems integrated. This must be scalable in order to integrate new ERPs in the system.

- Establish a communication system scalable, fast and homogeneous for communication with mobile devices.

To create information standard, a thorough analysis of the information which is handled by different ERP, should be made. Several information entities covering different modules that manage ERP systems will be created. The information for each entity will be different in each ERP system so it will be necessary to develop correlation between ERP information and information pertaining to the information standard. Subsequently established correspondences guide the transformation of the information carried out on each adapter.

The conversion information is implemented by performing transformations of XML files (Figure 2). For processing and more efficient parsing VTD-XML [36] will be used. 


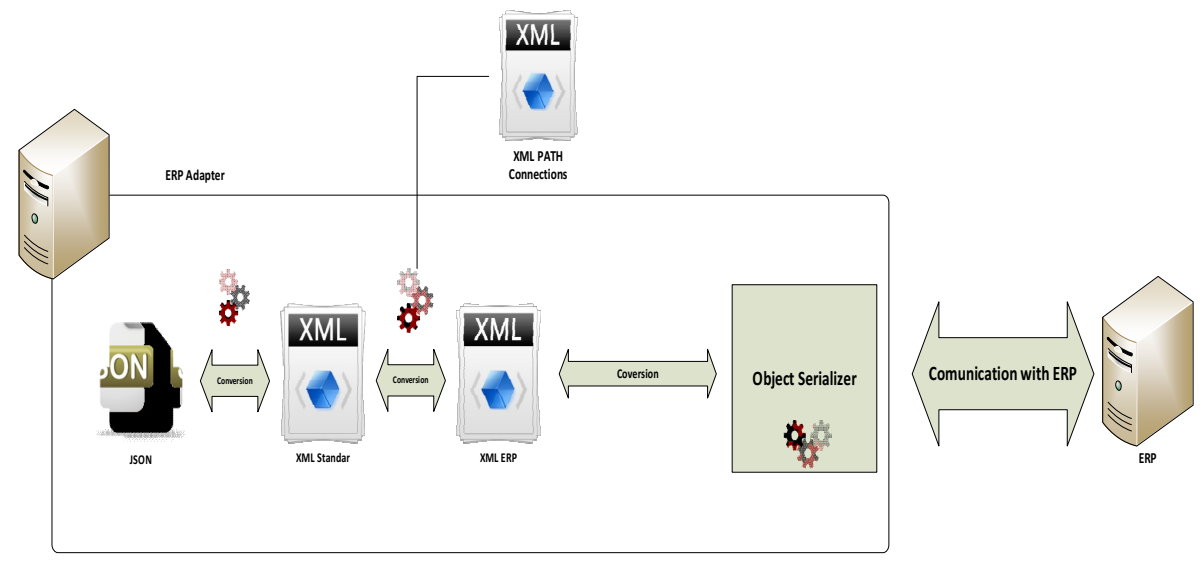

Fig. 2. Conversion of information in ERP Adapter

The communication interface that exist between mobile devices and adapters will be a collection of REST services common to all adapters. Web or mobile applications will communicate with REST services [35] [20] [19] [18] to perform operations on the ERP system. Each adapter must establish what services are active depending on the possibilities offered by the ERP system in each case.

\section{$4 \quad$ Results}

The mobilization of information and pre-sales and route accounting operations of the ERP to an Android mobile device has been proposed as the initial case study:

- Customer management

- Items management

- Invoices management

- Orders management

- Shipment management

To this end, adapters have been developed for each ERP system-integrated.

The development of these adapters has been carried out on the NET WEB API platform [15] [16] [17] [27]. Communication with each ERP has been done with SOAP web services in Microsoft Dynamic AX [25] and NAV [24] and using DI API in SAP Business One. [26] .The information that has been transferred covers the following information entities: Customers, Items, Orders, Invoices and Shipment. Information Correlations of each ERP to the established standard have been made. Figure 3 shows one of the tables with the established correlations in the Customer entity. 


\begin{tabular}{|c|c|c|c|}
\hline NAVISION (NAV) & AXAPTA (AX) & SAP BUSINESS ONE & STANDARD \\
\hline No & AccountNum & cardcode & numero \\
\hline Name & Name & CardName & nombre \\
\hline Name2 & NameAlias & CardFname & nombre2 \\
\hline Address & Address & Address & direccion \\
\hline Address & Address[2] & - & direccion2 \\
\hline City & City & MailCity & ciudad \\
\hline Phone No & [Type ='Phone']/Locator & Phone1 & telefono \\
\hline Price including Vat & InclTax & $\ldots$ & incluyelva \\
\hline VAT Registration No & VATNUM & VATRegNum & numerolva \\
\hline Gen. Bus. Posting Group & & - & genBusPostingGoup \\
\hline PostCode & ZipCode & ZipCode & codigoPostal \\
\hline Debit Amount & & Balance & cantidadDebito \\
\hline Credit Amount & & $\ldots$ & cantidadCredito \\
\hline E-Mail & [Type ='Email']/Locator & e_mail & eMail \\
\hline No. Series & NumberSequenceGroup & - & numeroSecuencia \\
\hline VAT Bus. Posting Group & Tax Group & VATGroup & grupoDelmpuestos \\
\hline No. of Orders & & - & numeroPedidos \\
\hline No. of Invoices & & $\ldots$ & numerofacturas \\
\hline Customer Posting Group & CustGroup & GroupCode & grupoCliente \\
\hline
\end{tabular}

Fig. 3. Information Correlations

Each ERP adapters provides a common service interface in communication services with mobile devices. The application will communicate with the different ERP setting the adapter configuration with the one you want to connect, then it will perform the same operations regardless of the ERP at the other end of the communication.

For example, if we want to perform a search for an item, the following request will be made to the adapter, independently of the adapter involved.

POST request with the following JSON data to web service "/sap/item /search ' adapter in this case SAP Business One:

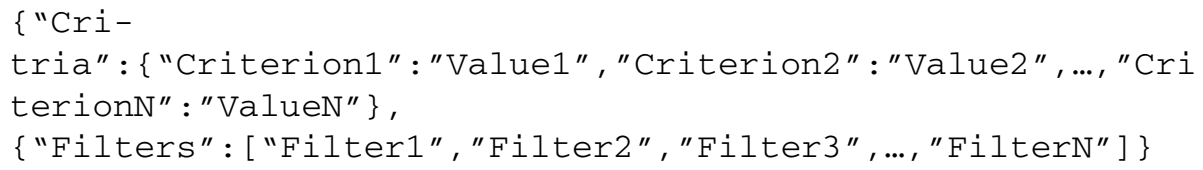

The criteria indicates the record being searched and filters the information that you want to retrieve of that record. The response obtained after doing the request to this service shall comprise the information specified by the filters of all items that match the criteria sent Figure 4.

The developed application has a set of modules corresponding to the entities and operations of ERP mobilized Figure 5 A). Can be made in different ERP systems management operations such as search items Figure 5 B), search invoices Figure 5 D) orders creation Figure 5 C) and so on.

The mobile application offers a configuration module Figure 6. C) and D) where you must specify the ERP system which connected to the application at each moment. Options such as barcode scanning and creating PDF documents Figure 6 A) and B) have been developed as examples of the features that can be added by taking advantage of characteristics of mobile devices. 


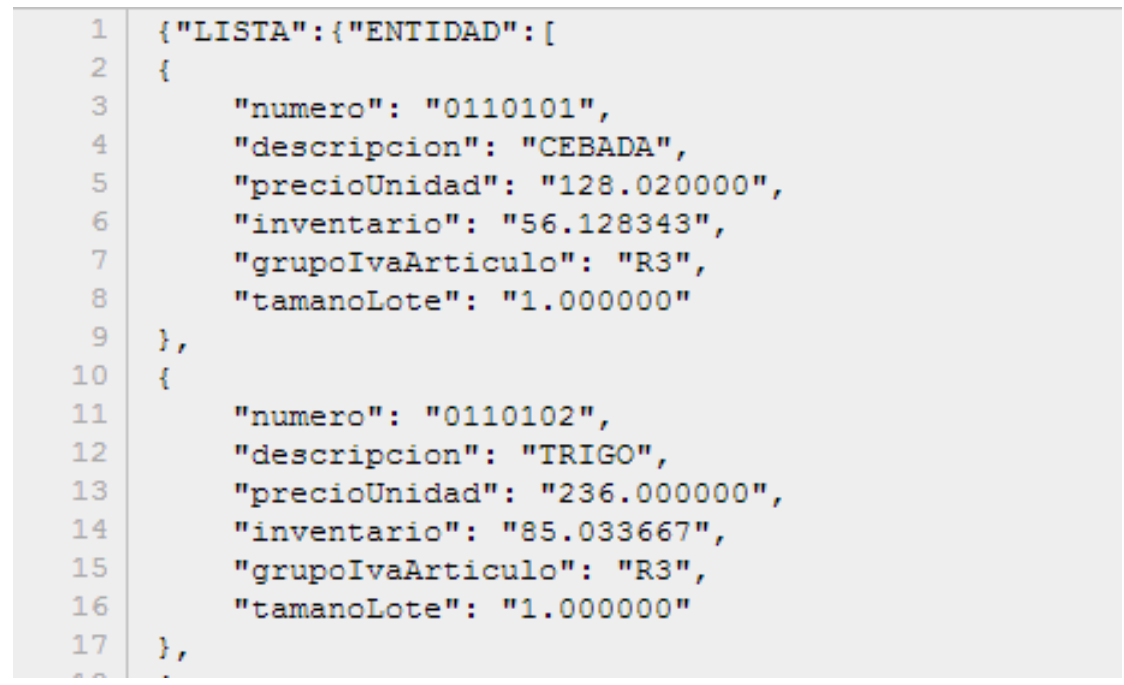

Fig. 4. Search response
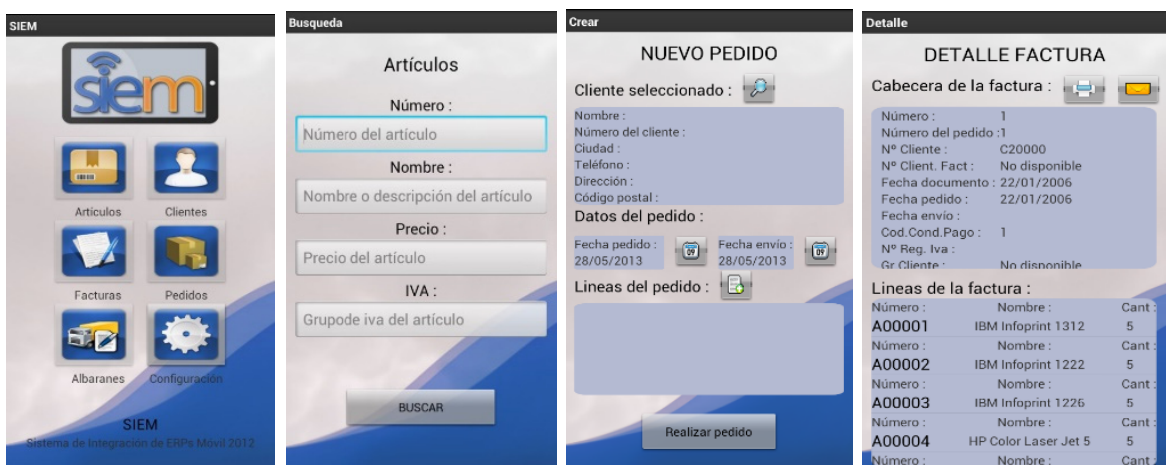

Fig. 5. A) Home menu B)Item Search C) New Order D)Bill Detail
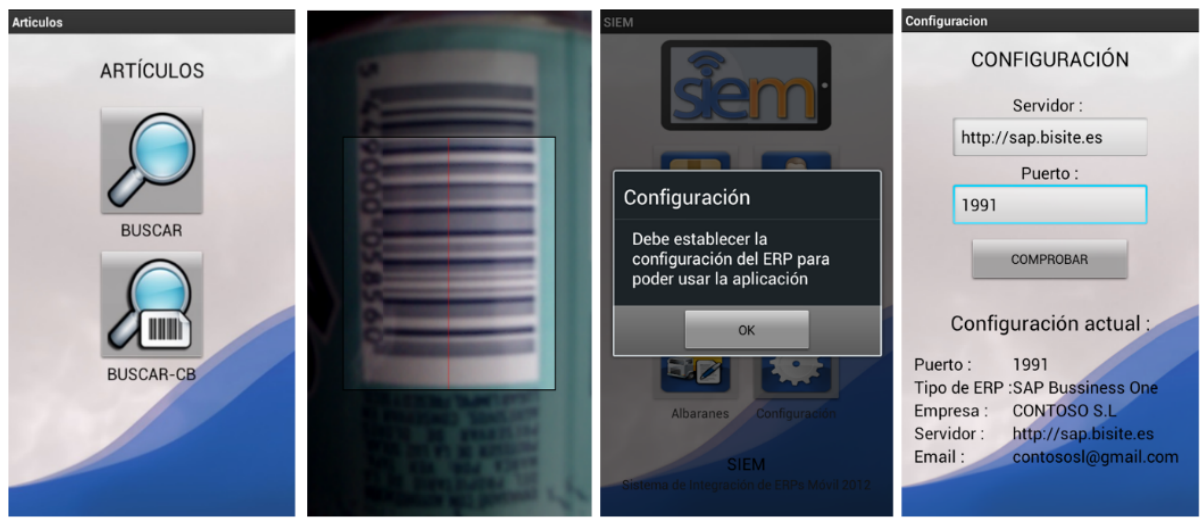

Fig. 6. A) Item Codebar Search B) Codebar Scan C) \& D) Configuration Module 
The developed application is able to perform the operations described below in integrated ERP systems. To perform the different operations which are available on the adapter, simply connect the adapter and set the adapter configuration imposed. Having established the configuration you can access the various modules of the application and perform the operations that enable the adapter.

\section{Conclusions and Future Works}

This developed system allows transferring characteristics and pre-auto-sales tasks to mobile Android devices with different ERP systems on the market such as Microsoft Dynamics AX, Microsoft Dynamics NAV and SAP Business One. Creating a common standard of information enables to establish in the same way communication between the mobile device and any adapter. This facilitates the development of applications for different ERP systems. The process of defining the standard of information has been a complicated process that has required an exhaustive research to locate the different ERP information and its correlation with the standard. The process of publishing the information in different ERP is varied. In Microsoft ERPs it is done through a series of SOAP web services to be configured and to provide remote access publishing. In the case of SAP access to information is done by DI API. This process is simplified with the established standard because access to information is common for ERPs. An application that uses this developed system has been carried out in Android's platform. This makes possible a subsequent development of applications in other platforms such as IOS, Blackberry OS or Windows Phone, even in web applications.

Increasing adapter's usefulness is proposed as a future project [14] [13] [12] [11]. Currently, the developed adapters only cover a small usefulness of every possible operations of the ERP. Thanks to the platform where they have been created, more services can be added later to different functional modules of the ERP. This will allow increasing the usefulness of the developed application or even develop other applications related with other functional module of the ERP.

\section{References}

1. Serdeira Azevedo, P., Romão, M., Rebelo, E.: Advantages, Limitations and Solutions in the Use of ERP Systems (Enterprise Resource Planning) - A Case Study in the Hospitality Industry. 5, 264-272 (2012)

2. Johansson, B., Ruivo, P.: Exploring Factors for Adopting ERP as SaaS (9), 94 - 99 (2013)

3. Clemens, B., Cata, T., Hackbarth, G.: Mobile Device Considerations for Supply Chain and ERP Related Systems, 16 pages (2012)

4. Al Bar, A., Mohamed, E., Khursheed Akhtar, M., Abuhashish, F.: A preliminary review of implementing Enterprise Mobile Application in ERP environment 11(04), 77-82 (2011)

5. Zur Muehlen, M., Nickerson, J.V., Swenson, K.D.: Developing web services choreography standards-the case of REST vs. SOAP (40), 9-29 (2005)

6. Agüero, J., Rebollo, M., Carrascosa, C., Julián, V.: MDD-Approach for developing Pervasive Systems based on Service-Oriented Multi-Agent Systems 
7. Závodská, A., Šramová, V., Aho, A.-M.: Knowledge in Value Creation Process for Increasing Competitive Advantage. Advances in Distributed Computing and Artificial Intelligence Journal 1(3), 35-47 (2012)

8. Corchado, J.M., Fyfe, C.: Unsupervised neural method for temperature forecasting. Artificial Intelligence in Engineering 13(4), 351-357 (1999)

9. Fdez-Riverola, F., Corchado, J.M.: CBR based system for forecasting red tides. Knowledge-Based Systems 16(5), 321-328 (2003)

10. Tapia, D.I., Abraham, A., Corchado, J.M., Alonso, R.S.: Agents and ambient intelligence: case studies. Journal of Ambient Intelligence and Humanized Computing 1(2), 85-93 (2010)

11. Corchado, J.M., Lees, B.: Adaptation of cases for case based forecasting with neural network support. Soft Computing in Case Based Reasoning, 293-319 (2001)

12. Corchado Rodríguez, J.M.: Redes Neuronales Artificiales: un enfoque práctico. Servicio de Publicacións da Universidade de Vigo, Vigo (2000)

13. Bajo, J., Corchado, J.M.: Evaluation and monitoring of the air-sea interaction using a CBR-agents approach. In: Muñoz-Ávila, H., Ricci, F. (eds.) ICCBR 2005. LNCS (LNAI), vol. 3620, pp. 50-62. Springer, Heidelberg (2005)

14. Fraile, J.A., Bajo, J., Corchado, J.M., Abraham, A.: Applying wearable solutions in dependent environments. IEEE Transactions on Information Technology in Biomedicine 14(6), 1459-1467 (2011)

15. Corchado, J.M., De Paz, J.F., Rodríguez, S., Bajo, J.: Model of experts for decision support in the diagnosis of leukemia patients. Artificial Intelligence in Medicine 46(3), 179200 (2009)

16. De Paz, J.F., Rodríguez, S., Bajo, J., Corchado, J.M.: Case-based reasoning as a decision support system for cancer diagnosis: A case study. International Journal of Hybrid Intelligent Systems 6(2), 97-110 (2009)

17. Tapia, D.I., Rodríguez, S., Bajo, J., Corchado, J.M.: FUSION@, a SOA-based multi-agent architecture. In: International Symposium on Distributed Computing and Artificial Intelligence (DCAI 2008), pp. 9-107 (2008)

18. Corchado, J.M., Aiken, J.: Hybrid artificial intelligence methods in oceanographic forecast models. IEEE Transactions on Systems, Man, and Cybernetics, Part C: Applications and Reviews 32(4), 307-313 (2002)

19. Corchado, J.M., Aiken, J., Rees, N.: Artificial intelligence models for oceanographic forecasting. Plymouth Marine Laboratory (2001)

20. Rodríguez, S., Pérez-Lancho, B., De Paz, J.F., Bajo, J., Corchado, J.M.: Ovamah: Multiagent-based adaptive virtual organizations. In: 12th International Conference on Information Fusion, FUSION 2009, pp. 990-997 (2009)

21. Tapia, D.I., Alonso, R.S., De Paz, J.F., Corchado, J.M.: Introducing a distributed architecture for heterogeneous wireless sensor networks. In: Omatu, S., Rocha, M.P., Bravo, J., Fernández, F., Corchado, E., Bustillo, A., Corchado, J.M. (eds.) IWANN 2009, Part II. LNCS, vol. 5518, pp. 116-123. Springer, Heidelberg (2009)

22. Rodríguez, S., de Paz, Y., Bajo, J., Corchado, J.M.: Social-based planning model for multiagent systems. Expert Systems with Applications 38(10), 13005-13023 (2011)

23. Pinzón, C.I., Bajo, J., De Paz, J.F., Corchado, J.M.: S-MAS: An adaptive hierarchical distributed multi-agent architecture for blocking malicious SOAP messages within Web Services environments. Expert Systems with Applications 38(5), 5486-5499

24. Studebaker, D.: Programming Microsoft ${ }^{\circledR}$ Dynamics ${ }^{\mathrm{TM}}$ NAV 2009. Packt Publishing Ltd., Birmingham (2009) ISBN 978-1-847196-52-1 
25. Ansari, A.: Inside Microsoft Dynamics AX 2012. Microsoft Press, United States of America (2012) ISBN: 978-0-7356-6710-5

26. Niefert, W.: SAP® Business ONE Implementation. Packt Publishing Ltd., Birmingham (2009) ISBN 978-1-847196-38-5

27. Zeitler, A., Kheyrollahi, A.: Pro ASP.NET Web API: HTTP Web Services in ASP.NET (2013) ISBN-13: 978-1430247258

28. Tapia, D.I., De Paz, J.F., Rodríguez, S., Bajo, J., Corchado, J.M.: Multi-agent system for security control on industrial environments. International Transactions on System Science and Applications Journal 4(3), 222-226 (2008)

29. Borrajo, M.L., Baruque, B., Corchado, E., Bajo, J., Corchado, J.M.: Hybrid neural intelligent system to predict business failure in small-to-medium-size enterprises. International Journal of Neural Systems 21(04), 277-296 (2011)

30. De Paz, J.F., Rodríguez, S., Bajo, J., Corchado, J.M.: Mathematical model for dynamic case-based planning. International Journal of Computer Mathematics 86(10-11), 17191730 (2009)

31. Bajo, J., De Paz, J.F., Rodríguez, S., González, A.: Multi-agent system to monitor oceanic environments. Integrated Computer-Aided Engineering 17(2), 131-144 (2010)

32. Corchado, J.M., Bajo, J., De Paz, J.F., Rodríguez, S.: An execution time neural-CBR guidance assistant. Neurocomputing 72(13), 2743-2753 (2009)

33. Panorama Consulting. Panorama Consulting, http: / /panorama-consulting.com/

34. Jitterbit, http: //www.jitterbit.com/

35. JSON, http: //www. json. org/

36. VTD-XML, http://vtd-xml.sourceforge.net/persistence.html

37. https://itunes.apple.com/es/app/ sap-business-one/id392606876? mt=8

38. https://play.google.com/store/apps/details?id=b1. mobile.android\&hl=es_419

39. http://www.windowsphone.com/es-es/store/app/ sap-b1-mobile-apps / a6d482e3-b1e1-40f0-8f59-89c52b2df4c6 